
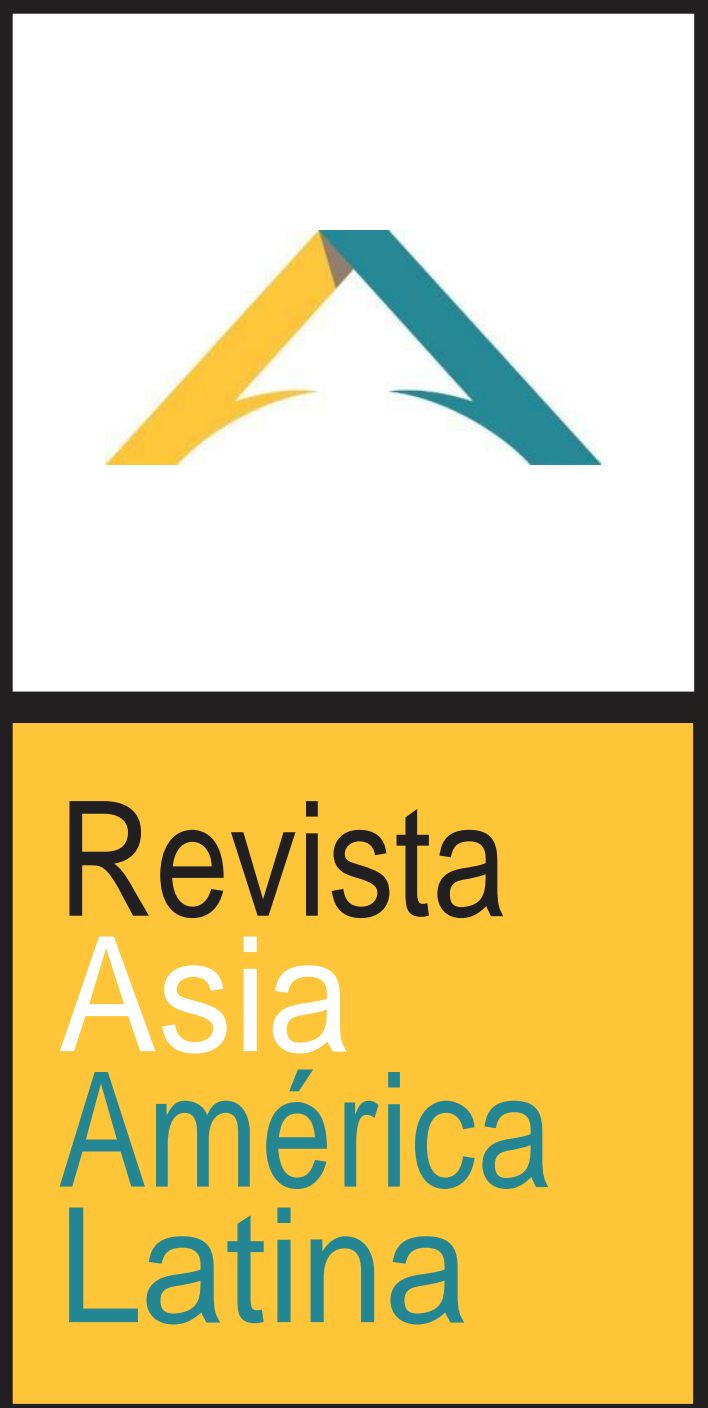

ISSN 2524-9347

Grupo de Estudios sobre Asia y América Latina Instituto de Estudios de América Latina y el Caribe Universidad de Buenos Aires

EU

DE BA 
La utopia y la experiencia de viaje a la República Popular China: el prisma ideológico en Vicente Lombardo Toledano y Pablo Neruda (1949-1951)

LUIS ABRAHAM BARANDICA MARTÍNEZ

\title{
LA UTOPÍA Y LA EXPERIENCIA DE VIAJE A LA REPÚBLICA POPULAR CHINA: EL PRISMA IDEOLÓGICO EN VICENTE LOMBARDO TOLEDANO Y PABLO NERUDA (1949-1951)
}

\author{
UTOPLA AND TRAVEL EXPERIENCES TO THE \\ PEOPLE'S REPUBLIC OF CHINA: THE \\ IDELOGICAL PRISM IN VICENTE LOMBARDO \\ TOLEDANO AND PABLO NERUDA (1949-1951)
}

\section{Luis Abraham Barandica Martínez}

Universidad Nacional Autónoma de México abrahambarandica@gmail.com

Fecha de recepción: 10/07/2019

Fecha de aceptación: 12/03/2020

Resumen: En este trabajo se analiza literatura de viajes partiendo de la premisa de que aquello que se registra en los relatos tiene ya un prejuicio ideológico, y esta circunstancia puede llegar a identificarse, entenderse y explicarse. El texto está dividido en cinco secciones. La primera expone la idea de utopía como un marco de trasfondo en la relatoría de viajes. Un segundo paso es identificar la asociación de esa idea de utopía con la idea de progreso, que permite encauzar la acción de los hombres en la construcción material de una sociedad. Una tercera parte describe cómo se conjuntaron los anteriores elementos en la construcción discursiva de los regímenes comunistas. Se analiza la promesa de un lugar y una organización donde se desenvolvería el verdadero progreso humano igualitario. La cuarta sección describe de forma históricoanalítica el proceso chino moderno hasta la instauración de la República Popular China; y la caracterización del viajero latinoamericano. Se analizan su vivencia y sus juicios en relación directa a las técnicas de hospitalidad del régimen asiático. Se concluye con una breve consideración retomando elementos propuestos por Paul Hollander y el marco inicial de la imaginación de una utopía.

Palabras clave: utopía, comunismo, viajes, República Popular China, Latinoamérica. 
La utopía y la experiencia de viaje a la República Popular China: el prisma ideológico en Vicente Lombardo Toledano y Pablo Neruda (1949-1951)

LUIS ABRAHAM BARANDICA MARTÍNEZ

\begin{abstract}
This work analyzes travel literature under the premise that what is recorded in the stories already has an ideological prejudice, and this circumstance can be identified, understood and explained. The text is divided into five sections. The first part exposes the idea of utopia as a background framework in the travel report. A second step is to identify the relationship of that idea of utopia with the idea of progress, which allows the channeling of the action of men in the material construction of a society. A third part describes how the previous elements were combined in the discursive construction of communist regimes. The promise of a place and an organization where true egalitarian human progress would unfold isfurther analyzed. The fourth section describes in a historical-analytical way the modern Chinese process until the establishment of the People's Republic of China; also the characterization of the Latin American traveler. Their experiences and judgments are analyzed in direct relation to the hospitality techniques of the Asian regime. It concludes with a brief consideration by retaking elements proposed by Paul Hollander and the initial framework of the imagination of a utopia.

Keywords: Utopia, Communism, Travels, People's Republic of China, Latin America
\end{abstract}

\title{
I. Introducción
}

El presente escrito analiza literatura de viajes partiendo de la premisa de que aquello que se registra en los relatos tiene ya un prejuicio ideológico, y esta circunstancia puede identificarse, entenderse y explicarse (Mannheim, 2004; Ricoeur, 2008). De esta forma se explora, en un primer momento, el camino de la relatoría de los viajes con una explicación política en el período moderno temprano, comenzando con la idea de utopía. Un segundo paso es la forma de ligar la idea de utopía con la idea de progreso, lo que permite encauzar de manera definitiva la acción de los hombres en la construcción de una sociedad, ejemplificándolo en la transformación revolucionaria. Una tercera fase es describir cómo se conjuntaron los anteriores elementos en la construcción discursiva del régimen comunista, heredero revolucionario del movimiento francés, en general y, comunista chino, en particular. Se analiza la promesa de un lugar y una organización donde se desenvolvería el progreso humano verdadero e igualitario. Se presenta en esta parte una descripción histórico-analítica en la que se engarzan los procesos de consolidación de la 
República Popular China con los visitantes, invitados, de América Latina. Luego se caracteriza a este viajero-peregrino y se analiza su vivencia y sus juicios en relación directa con las técnicas de hospitalidad del régimen asiático. Se concluye con unas breves consideraciones retomando elementos propuestos por Paul Hollander (Hollander, 1998; 2016) y una digresión sobre el influjo de la utopía. El texto está construido en cinco secciones que temporalmente limitan el trabajo a la época moderna y espacialmente cubren una perspectiva de proceso de historia mundial, a saber, el tránsito de ideas y la explicación ideológica y discursiva en Europa, América y Asia.

\section{La utopía}

En 1516 Tomás Moro (1478-1535) publicó su obra titulada De optimo rei publicae deque nova insula Utopia. ${ }^{1}$ En el libro narraba en voz de un viajero y guía que explicaba la situación particular, la existencia, organización y vida de una isla ficticia llamada Utopia (que significa: ningún lugar). El elemento principal de su argumentación, para este estudio, es plantear una sociedad hecha y vivida por hombres (Modoro, 2016). Pensamiento revelador de la maleabilidad de las prácticas y costumbres sociales, políticas e incluso religiosas.

Moro nació en Londres, fue hijo de Juan Moro, abogado, quien lo llevó a temprana edad al servicio de John Morton, canciller del rey Enrique VII, arzobispo y posteriormente cardenal. ${ }^{2}$ Con este mecenazgo, la carrera de Tomás estaba asegurada. Aun así, el joven Moro luego de dos años fue enviado a Oxford para adquirir pericia en retórica y lógica, que le serían de utilidad en la carrera de Leyes. Así, aproximadamente a los 16 años regresó a Londres y comenzó su práctica, posiblemente con su padre. Como estudiante de leyes tuvo una impronta de sus profesores humanistas, del studia humanitatis, es decir, de las lenguas del modelo educativo culto en la Edad Media. ${ }^{3}$ Su aprendizaje de latín y griego le permitió estar a tono con el movimiento humanista e iniciar correspondencia con egregios intelectuales, como Erasmo de Rotterdam. ${ }^{4}$ Sus mentores de griego, John Colt y William Grocyn, lo influyeron notablemente. Moro adquirió el idioma heleno y le sirvió, pues esporádicamente traducía del griego para incrementar sus ingresos. No es de extrañar, en este orden de ideas, que su obra la escribiera en latín, pero el nombre propio del lugar central del

\footnotetext{
${ }^{1}$ Sobre Moro existe una extensa bibliografía; en particular (Ackyrod, 2003; Davis, 1985).

${ }^{2}$ Enrique VII nació en 1457 y murió en 1509. Vencedor de Ricardo II, asumió la corona de Inglaterra en 1586.

${ }^{3}$ Sobre el modelo educativo en que se sustentó la educación griega como antecedente de las humanidades (Werner, 2002). Sobre los studia bumanitatis (Kristeller, 1982).

${ }^{4}$ Humanista y filósofo, nació en 1466 y murió en 1536 (Furey, 2006; Yoran, 2010).
} 
La utopía y la experiencia de viaje a la República Popular China: el prisma ideológico en Vicente Lombardo Toledano y Pablo Neruda (1949-1951)

LUIS ABRAHAM BARANDICA MARTÍNEZ

relato fuese en griego.

A pesar de tener en mente, según sus biógrafos católicos, la vocación religiosa, Tomás Moro siguió su vida secular, casándose por primera vez en 1505 con una joven adinerada de nombre Jean Colt, hija de uno de sus profesores; con quien tuvo cuatro hijos antes de enviudar en $1511 .^{5}$ Posteriormente, contrajo nupcias con Alice Middleton. Entre tanto su carrera ascendía: ingresó en el Parlamento en 1504, dio clases de Leyes en el salón Furnivall de 1503 a 1506; en 1507 obtuvo el cargo de Secretario financiero del Salón Lincoln y llegó a ser miembro influyente de la guilda de mercaderes. Regresó al Parlamento en 1510 y fue subsheriffen Londres según su participación en un juicio. De 1511 a 1518 fue un activo ciudadano de Londres, donde poco a poco ganaba prestigio como orador y abogado. Ese mismo año de 1518 entró al servicio del rey Enrique VIII. ${ }^{6}$

Su obra Utopía precisamente se gestó en un viaje que realizó Tomás Moro de Inglaterra a Flandes como miembro de una legación mercantil en mayo de 1515 (Marius, 1999, pp. 1-13). No regresó sino hasta octubre, aunque sus compañeros ya lo habían hecho en julio. Visitó Amberes, donde conoció a Peter Giles, un recomendado de Erasmo, y esta experiencia la incorporó en su texto. Hizo que Giles le presentara a un viajero ficticio llamado Raphael Hytholday, quien a su vez es la voz narrativa de la isla Utopía. No se tiene certeza de cuándo escribió el libro completo, pero su amigo, Erasmo, quien trianguló el encuentro, nos da constancia en una carta donde explica a otro amigo, en 1519, la hechura de Moro:

Cuando era adolescente [Moro] trabajó en un diálogo en el que defendía las doctrinas de Platón sobre el comunitarianismo [...] Publicó la Utopía con la intención de mostrar el porqué de las deficiencias de la sociedad; pero retrató sobre todo la nación inglesa porque la había estudiado y era la que mejor conocía. Escribió primero el libro segundo, en su tiempo libre; más tarde, cuando tuvo oportunidad, añadió el primer libro bajo la inspiración del momento. De ahí esa cierta desigualdad en el estilo. (Silva, 1998, p. 151)

Sin duda, su experiencia como abogado y su formación como humanista conocedor de los autores griegos lo llevaron a idear y elegir un diálogo como forma para escribir su libro.

No se cuenta con el espacio en esta oportunidad para detallar el

\footnotetext{
${ }^{5}$ La primera biografía en español data de 1617 y fue obra de Fernando de Herrera (Herrera, 2001; Neumeister, 2010, pp. 147-158).

${ }^{6}$ Enrique VIII, hijo y sucesor de Enrique VII, nació en 1491 y murió en 1547.

Ascendió al trono al morir su padre en 1509
}

Asia/ AméricaLatina, vol. 5, no 9, (2020), pp. 11-40. DOI: 10.33177/9.2 
La utopia y la experiencia de viaje a la República Popular China: el prisma ideológico en Vicente Lombardo Toledano y Pablo Neruda (1949-1951)

LUIS ABRAHAM BARANDICA MARTÍNEZ

contenido del libro y, antes de seleccionar ciertos pasajes, es preciso mencionar que su fama y reconocimiento como antecesor intelectual fue explícita antes de triunfar el movimiento comunista y después

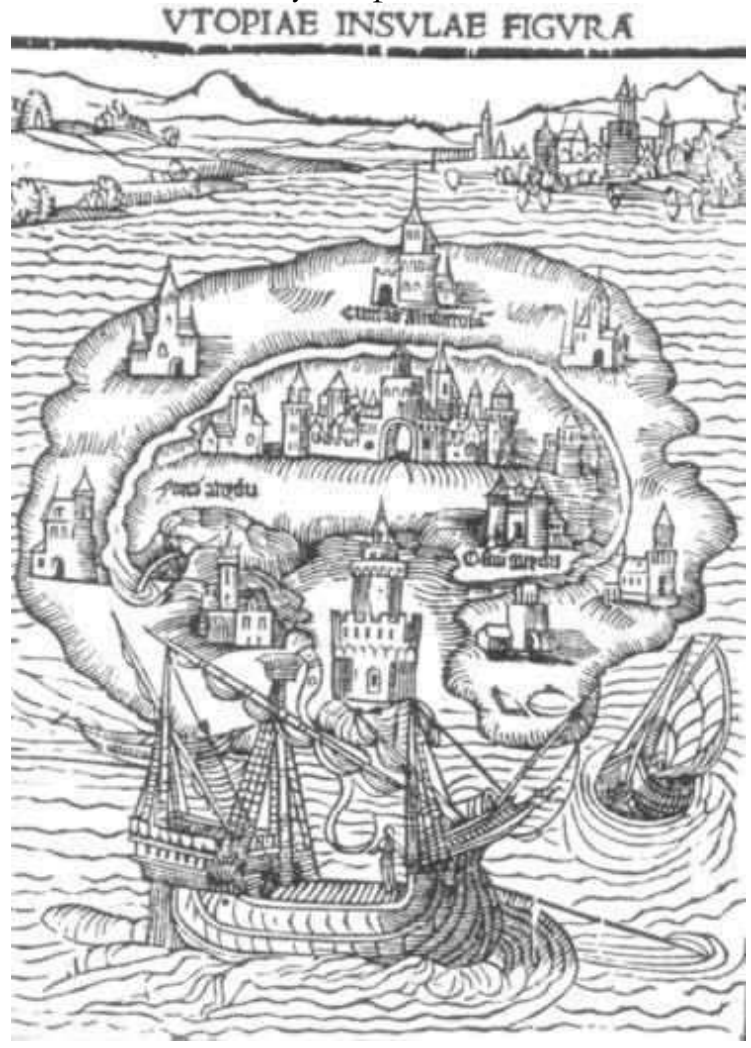

Imagen que ilustra la edición de Utopía de 1516 (Morvs, 1895).

Karl Kautsky (1854-1938) fue un pensador marxista que tuvo serias diferencias con los bolcheviques, escribió ampliamente acerca de Moro publicando su estudio en 1888 (Kautsky, 1888). El título precisamente es Tomás Moro y su Utopía [Thomas More und seine Utopie]. En este texto, Kautsky describe detalladamente la precedencia de Moro en el pensamiento socialista.

Años después, en un curso en Burdeos entre 1895 y 1896, otro pensador, Émile Durkheim, identificó en la raigambre del pensamiento comunista al autor inglés. ${ }^{7}$ Ampliamente señala al diferenciar las teorías socialistas de las comunistas:

${ }^{7}$ Émile Durkheim nació en 1858 y murió en 1917. Fue un filósofo francés que estableció formalmente la sociología, constituyendo el departamento de esta disciplina en la Universidad de Burdeos en 1895 y publicando su obra Las reglas del método sociológico. (Zeitlin, 2001). 
La utopía y la experiencia de viaje a la República Popular China: el prisma ideológico en Vicente Lombardo Toledano y Pablo Neruda (1949-1951)

\section{LUIS ABRAHAM BARANDICA MARTÍNEZ}

[...] las teorías comunistas sólo aparecen en la historia de forma muy esporádica. Son manifestaciones separadas entre sí, con harta frecuencia, por largos espacios de tiempo. De Platón a Thomas Moro median casi diez siglos y las tendencias comunistas que se pueden mostrar en algunos padres de la iglesia no bastan para superar esta solución de continuidad. De la Utopia (1518) [sic] a la Ciudad del Sol [de Tomasso de Campanella] (1623) hay más de un siglo de distancia, y después de Campanella hay que esperar al siglo XVIII para ver reaparecer el comunismo [...]. (Durkheim, 1987, p. 43)

En el tiempo en el que Durkheim escribe, aún considera al comunismo como un ejercicio teórico, más no tangible. Continúa:

Son sueños en los que solazan espíritus generosos y que llaman la atención y mantienen el interés a causa de esa misma generosidad y elevación, pero que al no responder a las necesidades actualmente sentidas por el cuerpo social, sólo actúan sobre la imaginación y permanecen infecundos en un plano práctico [...]. (p. 43)

Además, piensa que los propios autores de estas ideas las consideran sólo ficción, como apuntala citando el final del mismo libro -en una versión libre del latín- de Tomás Moro:

[...] no puedo adherirme a todo lo que acaba de ser contado sobre la isla de Utopía, reconozco que allí ocurren cosas que me gustaría que fueran imitadas por nuestras sociedades, a pesar de que no espero que tal cosa ocurra. (p. 44)

Más tarde y contradiciendo, en cierta medida, la perspectiva de Durkheim, en 1918 el líder triunfante de la Revolución Rusa Vladimir Ilych Lenin ordenó modificar, en el Jardín Alexandorvsy contiguo al palacio del Kremlin, una estela en honor a la familia Romanov, dinastía que gobernó Rusia como zares, para convertirla en un monumento a los pensadores revolucionarios. Entre los nombres grabados en la estela se encuentra Tomás Moro (Томас Mop en ruso) (Anónimo, 2012; Anónimo, 2014). 


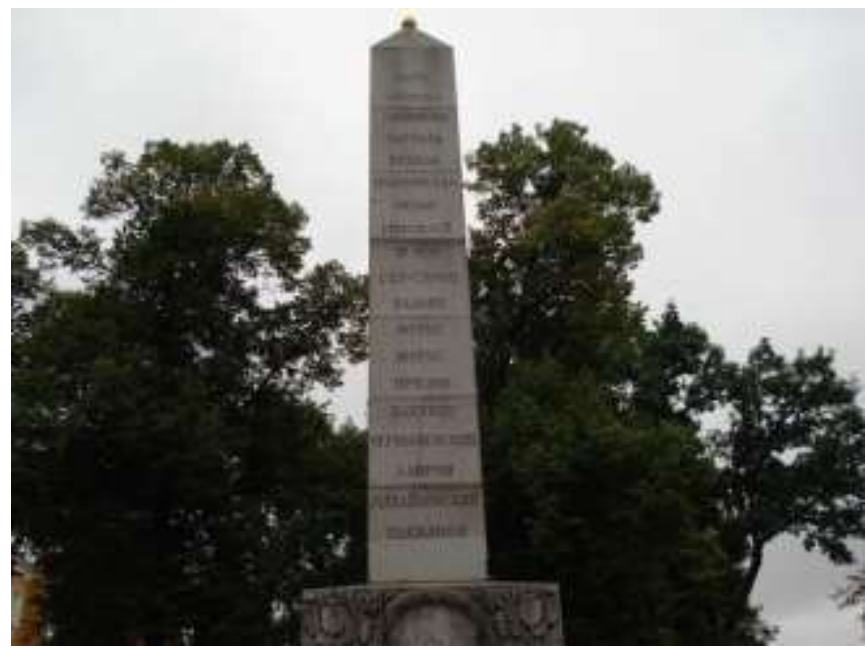

La estela de los pensadores revolucionarios. ${ }^{8}$

En 2013, el presidente ruso Vladimir Putin ordenó a su vez modificar el monumento y adecuarlo a su proyecto político de rescatar el pasado imperial ruso, zarista, y la estela volvió a llevar los nombres de la dinastía Romanov (Anónimo, 2014).

A continuación, se llama la atención en la construcción del pensamiento comunista hacia ciertos elementos de la obra de Moro. En la rememoración del viajero Raphael Hytholday de la isla de Utopía y en su diálogo con el mismo Moro, resaltan los aspectos de crítica a la "realidad" y la construcción de una sociedad ideada en una descripción en que se resuelven en otro espacio los problemas planteados en la crítica. Es decir, la sociedad criticada y su solución son contemporáneas, solo alejadas en la coordenada espacial, y el viajero es quien trae la noticia de aquella.

En la obra, ante los problemas sociales, la solución pasa por el análisis de las causas primeras. Así, no está a favor de alguna reforma, incluso si él como consejero del príncipe la impulsase. Proposición que le hace Moro a Raphael, quien la juzga fútil y agrega:

[...] en donde hay propiedad privada y donde todo se mide por el dinero, difícilmente se logrará que la cosa pública se administre con justicia [...] no hay sino un camino para salvar la República: la aplicación del principio de la igualdad de bienes [...]. (Moro, 2011, p. 88)

Además, agrega que “[...] estoy convencido de que jamás obtendrán

\footnotetext{
${ }^{8}$ Fotografía con autorización del autor. Recuperado en: https://moscudelarevolucion.blogspot.mx
} 
La utopía y la experiencia de viaje a la República Popular China: el prisma ideológico en Vicente Lombardo Toledano y Pablo Neruda (1949-1951)

LUIS ABRAHAM BARANDICA MARTÍNEZ

Asia Amb́rice

una justa distribución de los bienes o una organización satisfactoria de la vida humana hasta que sea abolida la propiedad privada en su conjunto" (Moro, 2011, p. 88). Aunque tal propuesta extrema la suaviza Moro replicando al viajero: “[...] es algo, que ni siquiera me atrevo aimaginar" (Moro, 2011, p. 88).

La comunidad de bienes es un principio ordenador de la república. Con ello, una justicia distributiva implícita al tiempo que un igualitarismo permiten estabilidad y son la base del orden y la paz; incluso de la felicidad como fin último del Estado: “[...] todas nuestras virtudes están abocadas al placer como a su fin y felicidad" (Moro, 2011, p. 137).

\section{Idea de progreso}

Como ya se mencionó, Durkheim había señalado en 1895-1896 lo espaciados temporalmente que se encuentran los teóricos comunistas. No obstante, en esos "vacíos" se desarrollaron ideas que serían sintetizadas por los posteriores pensadores. Así, una idea que es propia del siglo XVIII, como es la de progreso, marcaría, junto con la idea de razón, un nuevo hito en el estudio de las sociedades, que sería incorporado paulatinamente en las ideaciones utópicas. En torno a ello, aquí se analiza a Anne Robert Jacques Turgot y a Immanuel Kant. El movimiento amplio de la Ilustración (Aramayo, 2001, pp. 293-309) confluyó en varios sentidos en un puñado de pensadores paradigmáticos. En particular, para el análisis de la sociedad destaca la labor de Henri de Saint-Simon, quien a su vez influyó determinantemente a Auguste Comte y Karl Marx (Cosser, 1980, pp. 111-121; Zeitlin, 2001). ' Sin embargo, una disyuntiva surgió: estudiar la sociedad ¿para qué? Una opción fue conservarla; otra, reformarla; una más, modificar la sociedad radicalmente. Así, el hito revolucionario de 1789 -en el que participó Saint-Simon- llevó en su seno estas propuestas. Aunque variaron los actores, lo que de forma definitiva mostró la Revolución Francesa fue la capacidad del hombre para construir sus soluciones o intentarlo (Cosser, 1980, pp. 155-180).

En lo tocante a la idea de progreso, tema de la obra de J. B. Bury (1920; 1971), el autor la remite a los pilares del pensamiento económico moderno. La explica como la idea en que se acepta que la humanidad ha avanzado en el pasado, avanza actualmente y puede esperarse que continúe avanzando en el futuro.

\footnotetext{
${ }^{9}$ Saint-Simon nació en 1760 y murió en 1825. Fue un filósofo francés que participó en la lucha por la independencia de las colonias inglesas, y en los procesos de la revolución en Francia. Su obra voluminosa trató principalmente temas económicos y sociales. Es considerado fundador del socialismo utópico (Zeitlin, 1968, pp. 56-69). Existe versión en español también empleada en este trabajo y editada por Amorrortu (Zeitlin, 2001).
} 
El paso de una utopía contemporánea a una utopía separada por el tiempo y proyectada al futuro, que distingue este camino del milenarismo -que idealizaba el pasado-, es un aspecto fundamental para comprender la acción de los hombres. Del pasado nada se puede cambiar, lo contrario es el futuro. Así, se comienza a pensar que el mañana sería caracterizado por la libertad, la igualdad y la justicia individuales. Sin embargo, ¿cómo hacer palpable y cuantificable este progreso, aclarando que no es exclusivo de la época moderna? Varios autores ya habían expresado la convicción del cambio de las eras.

Protágoras reflexionó que la historia del hombre es la historia de sus luchas por librarse de la ignorancia primigenia, del miedo, de la esterilidad y de la incultura, y de la gradual ascensión a condiciones de vida cada vez mejores, consecuencia de un avance progresivo del conocimiento. (Nisbet, 1986)

Este progreso podría aplicarse a lo que se observaba en la forma de hacer las cosas. Así, un progreso material a partir del conocimiento y las artes, es decir, de las capacidades creadoras del hombre y, por extensión, de la sociedad. Anne Robert Jacques Turgot ${ }^{10}$ en 1750 dibujó en su Cuadro filosófico de los progresos sucesivos del espiritu bumano que:

El género humano, considerado desde su origen, parece a los ojos de un filósofo un todo inmenso que tiene, como cada individuo, su infancia y sus progresos [...] La masa total del género humano, con alternativas de calma y agitación, de bienes y males, marcha siempre aunque a paso lento- hacia una perfección mayor. ${ }^{11}$ (Turgot, 1991, pp. 3565)

Posteriormente, Immanuel Kant en su Idea de una historia universal (Kant, 1994) desde un punto de vista cosmopolita, señala en el primer principio que "Todas las disposiciones naturales de una criatura están destinadas a desarrollarse alguna vez completamente y con arreglo a un fin" (Kant, 1994, p. 19). $Y$ agrega en el cuarto principio:

El medio del que se sirve la Naturaleza para llevar a cabo el desarrollo de todas sus disposiciones es el antagonismo de las mismas dentro de la sociedad, en la medida en que ese antagonismo acaba por convertirse

\footnotetext{
10 Turgot nació en 1717 y murió en 1781, fue un político y filósofo francés. Su obra Tableau philosophique des progrès successifs de l'ésprit humain fue inicialmente un discurso pronunciado en latín, en la Sorbona en 1750.

${ }^{11}$ La misma idea de perfeccionamiento progresivo (Condorcet, 1822)
} 
La utopía y la experiencia de viaje a la República Popular China: el prisma ideológico en Vicente Lombardo Toledano y Pablo Neruda (1949-1951)

LUIS ABRAHAM BARANDICA MARTÍNEZ

en la causa de un orden legal de aquellas disposiciones. (Kant, 1994, p. 20)

Además, en el octavo principio:

Se puede considerar la historia de la especie humana en su conjunto como la ejecución de un plan oculto de la Naturaleza para llevar a cabo una constitución interior y -a tal fin- exteriormente perfecta, como el único estado en el que puede desarrollar plenamente todas sus disposiciones en la humanidad. (Kant, 1994, p. 23)

En sus textos, Kant encauza el mejoramiento moral de la humanidad de forma paulatina. Pensadores posteriores ligaron estas dos consideraciones y unificaron lo material y lo moral. En el siglo XIX fue una corriente que se incorporó a la argumentación de los procesos europeos como los superiores, centrales o avanzados. Sin embargo, fue en la periferia que sucedió el segundo movimiento revolucionario triunfante: en Rusia. ${ }^{12}$

\section{La promesa del comunismo: un progreso hacia la utopía en la República Popular China}

El proceso revolucionario ruso de 1917 y la instauración de un régimen dieron realidad al proyecto que durante décadas abanderaba una facción política. El socialismo llegó al poder con las cargas de interpretación materialista y humana nacidas de la Ilustración y del largo proceso industrial decimonónico. Así, los hombres eran actores conscientes de la transformación social y llevaron su ideario a la realidad. La utopía, como resultado de la aplicación del progreso no en un lejano futuro, sino en el presente y dirigido por una vanguardia revolucionaria, fue un modelo que prometía justicia e igualdad expeditas. En regiones donde la desigualdad, la injusticia y la explotación cundían, esta corriente de ideas y de proyecto político podría recabar un apoyo substancial. Cabe mencionar que en diferentes regiones del globo no era necesaria la importación del concepto de justicia, ya que en las tradiciones de otros pueblos no es un concepto ajeno. Es decir, no se debe considerar que solo en Europa existía el malestar por las acciones injustas; en otras latitudes, las propias tradiciones locales exigían una distribución equitativa de cargas y responsabilidades.

En el caso chino es revelador el trabajo de Jorge E. Malena con relación al concepto de justicia expresado en la escritura china (Malena, 2012). La

\footnotetext{
12 Un acercamiento general sobre los antecedentes ideológicos del movimiento socialista está en (Wilson, 1972; Priestland, 2010; Carr, 1966)
} 
escritura china se formó a partir de dibujos inspirados directamente en la naturaleza. Poco a poco el nivel pictográfico ascendió a dos vertientes: una en relación al juego de la metáfora del significado y la otra en relación a su pronunciación; así, tenemos la vertiente ideográfica y la logográfica. En el caso del concepto abstracto de justicia “justicia” (法, fă) al estudiar la etimología del hanzi, carácter, podemos aproximarnos a lo que se piensa y asocia sobre la idea en China. ${ }^{13}$

La forma antigua de escribir justicia es 㾮 , que se pronuncia 'fa' (hoy la manera simplificada se escribe 法). El carácter está conformado por 3 partes:

(1) A la derecha, el carácter 廌 ₹̧bì, que se refiere a un animal divino que, según la mitología, podía distinguir entre el bien y el mal. La gente acudía a él cuando debía juzgarse una disputa, porque éste siempre embestía con su cuerno a quien no tenía la razón.

(2) En la porción inferior, el carácter 去 qù, que significa el verbo "ir" porque el animal divino 'iba' en contra del malvado.

(3) A la izquierda el carácter 水 shur o “agua", porque se entiende que un hecho justo es llano 'como la superficie del agua. (Malena, 2012)

Por otra parte, encontramos que "lo justo" 義 yì, está más cercano a lo que se entiende como "lo correcto". El mismo hanzi está compuesto por dos caracteres preexistentes: una parte superior 羊 yáng "oveja” y una parte inferior 我 wö “yo" (que a su vez se compone de 手shŏu "mano" más 戈 gee "lanza").

¿Por qué en chino 'lo justo' reúne a 'oveja' y a 'yo'? Porque según los chinos 'lo justo logra someter el egoísmo y convertirlo en algo dócil como una oveja". Pasando a otro carácter, en este caso 'ley' o 法 則 făzé, el mismo reúne al conocido carácter 'justicia' (法) y al carácter 則 zé cuyo pictograma está compuesto por 'cortar' y 'dinero'. Ello nos remitiría a la idea de 'justicia distributiva' de Aristóteles. Otro concepto interesante para conocer su origen etimológico es el de 'equidad': 公平 göngping. El mismo se compone por dos caracteres: 公 'lo público' y 平 'nivelar'. Este término se acerca a la equitas romano-cristiana, es decir el instrumento de humanización de la norma en función del caso concreto. (Malena, 2012)

En el caso de esa búsqueda de justicia y equidad, China ofrece un panorama paradigmático en los siglos XIX y XX: en el proceso de la decadencia

${ }^{13}$ En relación a la transliteración de los caracteres chinos, hanzi, se ha empleado en el texto el sistema pinyin, y se ha escrito en cursivas luego del hanzi. No obstante, en nombres o conceptos ya reconocidos y en las citas textuales se ha respetado el usado originalmente por los autores. 
La utopía y la experiencia de viaje a la República Popular China: el prisma ideológico en Vicente Lombardo Toledano y Pablo Neruda (1949-1951)

LUIS ABRAHAM BARANDICA MARTÍNEZ

Asia. Amśica
istins

22

del modelo imperial y las crisis empujadas por la presencia de europeos con un proyecto político y una flota armada para sustentarlo (North, 1965). La respuesta ligó el sentimiento de humillación y la construcción de una identidad victimista, que se acentuó con las grandes rebeliones populares del siglo XIX (la Taping y la de los Boxer) (Bianco, 1970; Breve historia moderna de China, 1980; Chesneaux, 1972; Jones y Khun, 1995, pp. 107-162).

El discurrir histórico del proceso puede comenzar a principios del siglo XIX, en 1816, cuando Inglaterra emergía de una transformación industrial y se convertía en potencia. La corona inglesa envió a su embajador Lord Amherst a la corte china de Beijing para buscar un acuerdo en el trato comercial, de preferencia de manera diplomática. Sin embargo, la tradición imperial china consideraba esta condición como impensable, ya que todo extranjero tenía que someterse a la soberanía del 皇 帝 Huangdi o Emperador, que unificaba en su persona la calidad de monarca e Hijo del Cielo y, por tanto, tenía preeminencia sobre otras cualesquiera entidades políticas, ya que incluso su responsabilidad cubría elementos naturales que permitían las buenas cosechas. En consecuencia, el embajador europeo tenía que hacer la ceremonia del吒头 Kòutóu que consistía en inclinarse y realizar postraciones, en reconocimiento de la superioridad del emperador Manchú, sin contar que se le consideraría como tributario de un monarca superlativo -aspectos que fueron inaceptables para Amherst-. Esta práctica era común en el este de Asia, incluso era un paso obligado para tener reconocimiento de China y un camino para el comercio a través del intercambio de obsequios (Fairbank, 1942, pp. 129-149).

Unas dos décadas después, el empuje industrial, las naves de vapor, la producción de metales, la mejora tecnológica en cañones y armas de fuego y en las técnicas en general, llevaron a un progreso material y en calidad de producción. De esta forma, los ingleses acrecentaron su confianza gracias a estas circunstancias e intentaron nuevamente llegar a un acuerdo con el imperio en China. La flota británica controlaba las principales rutas en los mares, ya que había derrotado a Napoleón, y Rusia era eminentemente un imperio terrestre, e imponía tratados comerciales leoninos. El objetivo de los comerciantes fue no solo mercadear con China sino "abrirla", es decir, controlar el intercambio, las rutas y obtener privilegios en los puertos (Fairbank, 1995, pp. 213-265).

Las tensiones subieron por el intento del control estatal chino del intercambio con los extranjeros de países europeos. El mercado chino no compraba productos ingleses, por lo que se recurrió a un elemento de alta demanda en el imperio: el opio. Una característica es que es un producto que se consume, por lo que constantemente incrementa la demanda. Así, el tráfico de la droga permitió a los ingleses obtener pingües ganancias. Esta situación se intentó controlar regulando el consumo y prohibiendo la droga en China, lo que redundaría en un enfrentamiento directo de intereses; hasta que para 
solucionar el diferendo comercial se iniciaron las hostilidades. El opio que se comercializaba con grandes ganancias en China era pasado por contrabando. Por esta razón las autoridades locales chinas o eran corrompidas para ingresar la mercancía obteniendo de ello verdaderas fortunas o, si cumplían con su deber aduanal, imposibilitaban la entrada de la droga a la nación, evitaban el tránsito y capturaban a los traficantes. Los ingleses acudieron a su flota para asegurarse este comercio y destruir cualquier viso de competencia manufacturera china, $\mathrm{y}$ lanzaron una campaña militar contra el Imperio. El conflicto se conoce como Guerra del Opio y conllevó a la derrota china y la captura de puertos y el logro de concesiones comerciales. Se establecieron, pues, los Tratados Desiguales (Fairbank, 1995, pp. 213-265).

Las posesiones extranjeras en puertos chinos -antes prohibidas- y las concesiones obtenidas como botín de guerra hicieron mella en el orden y la estructura imperial chinos. Al fin y al cabo, habían sido derrotados militarmente y al estar fundamentada la dinastía en su preponderancia militar y administrativa, constituyó un golpe doble y desolador. La descomposición de la dinastía Manchú no se pudo detener pese a los esfuerzos de algunos funcionarios. La familia, cuyo origen se ubicaba en la periferia al norte de la China histórica, acrecentó su incapacidad para hacerse cargo del gobierno central. En esta circunstancia, una fuerza centrífuga ocasionaba que las provincias quitaran autoridad al centro. Es decir, se presentó una fuerza disgregadora que, aunada al aumento de población y las malas cosechas, ocasionaron desde mitad del siglo una serie de explosiones sociales de descontento; entre ellas, las rebeliones Taiping y Boxer ya mencionadas. Sin olvidar el auge de las sociedades secretas que buscaban restablecer el orden expulsando a los Manchú y restaurando el poder en una dinastía étnicamente china. En este entorno negativo, aquellas propuestas, que a pesar de venir del exterior proponían una nueva fortaleza y recomposición social, hicieron su aparición combinándose con las tradiciones locales.

Por su parte, el intento del poder central por acallar estos movimientos fue doble: militar, por un lado, con el auxilio de fuerzas externas (europeas) y, por otro, con un programa de modernización militar y reformas estructurales. Aspecto este último truncado por la actividad de Japón, que tomó ventaja de su temprano -en comparación con China- progreso tecnológico, y para evitar que se convirtiera en competencia entabló una serie de peticiones con el objetivo de desencadenar una guerra. ${ }^{14}$ La primera guerra sino-japonesa, entre 1894 y 1895, destruyó el intento

\footnotetext{
${ }^{14}$ La respuesta japonesa a las circunstancias cambiantes en el este de Asia se benefició correlativamente de la fuerza de atracción que tenía el mercado chino. Le dio tiempo de modificar su estructura política en 1868, organizándose un movimiento que instauró una soberanía autoritaria en la figura del Tenno, llamándose Restauración Meidyi. Una de las primeras consignas fue unificar el esfuerzo militar y con ello se
} 
La utopía y la experiencia de viaje a la República Popular China: el prisma ideológico en Vicente Lombardo Toledano y Pablo Neruda (1949-1951)

LUIS ABRAHAM BARANDICA MARTÍNEZ

Asia Amb́rica
Lstins

24

chino de modernización militar y dejó prácticamente al poder central desarticulado. Los principales puertos eran controlados por extranjeros y la dinastía solo se podía mantener con su apoyo y anuencia.

Esta lamentable situación ocasionó el caos y dio a los cabecillas provinciales, que organizaban sus ejércitos privados, poderes locales autoritarios. En estas circunstancias, el líder del movimiento republicano chino Sun Yatsen aglomeró el descontento y se lanzó a la revolución para derrocar a la dinastía y al Imperio. En el ideario de Sun existe una propuesta que se conoce como los tres principios del pueblo 三民主義 sān min ₹hŭyì. En su trasfondo podrían encontrarse aquellas constantes de justicia y equidad. Los principios eran 民族主義; Minzźn zhŭyì, que el mismo Sun equiparaba a nacionalismo o al “gobierno del pueblo".民權主義; Mínquán ₹hŭyiz, que es decisión del pueblo que se asemejaría a la democracia y民生主義; Minshēng 汭ŭyi, que significaría bienestar del pueblo o "gobierno para el pueblo". ${ }^{15}$

A pesar de que la Revolución de 1911 derrocó al Imperio, las fuerzas de Sun Yatsen no eran capaces de mantener al país unido y se generó más caos y disgregación. ${ }^{16}$ La naciente República China (Zhonghua minguo) fue endeble. Aparecieron caudillos militares regionales encabezados por Yuan Shikai, quien en un golpe contrarrevolucionario quiso restablecer el Imperio, fundando él mismo una dinastía. Es importante mencionar que los países europeos no pudieron ejercer la acostumbrada intromisión favoreciendo a los caudillos que les asegurasen más concesiones por el hecho de estar librando una guerra en Europa, la Primera Guerra Mundial. Este acontecimiento también repercutió en un actor de la periferia: Rusia, que, como ya se mencionó, vivió un convulso período revolucionario. En efecto, la descomposición y el descontento hacia la dinastía Romanov estallaron en el Imperio Ruso durante la Primer Guerra Mundial -aunque tenía sus antecedentes tras la derrota europea contra Japón en la guerra de 1904-1905-.

La facción bolchevique liderada por el revolucionario Vladimir U. Lenin logró, luego de varias radicalizaciones y disputas internas, establecer la Primera Revolución Socialista triunfante en 1917. Con la formación estatal comunista, la ideología cobró carta de naturalización en política estatal práctica. El Ejército Rojo logró defender al naciente régimen y muy pronto la Rusia bolchevique rescindió los Tratados Desiguales de su antecesor imperial con respecto a China. Lo que mostraba, sin lugar a dudas, su cariz antiimperialista.

convirtió en una amenaza para China. Efectivamente existió una carrera armamentista entre Japón y China a finales del siglo XIX (Makito, 2011).

${ }^{15}$ Sobre las tempranas influencias socialistas en Sun Yat-sen (Wells, 2001, pp. 26 y ss.).

${ }^{16}$ En lo sucesivo una primera versión se halla en Barandica, 2013, pp. 11-20. 
La organización que conformó Sun Yatsen se transformó en el partido nacionalista chino o Guomindang, que bajo su liderazgo estableció buenos lazos de apoyo con el Estado soviético. En China, como en otras partes del mundo, se organizaron partidos comunistas que contaron con el apoyo de Lenin. En Rusia, los bolcheviques, en 1918, renombraron su Partido Social Demócrata a Comunista. En 1919, el mismo Lenin fundó la Tercera Internacional, con cuya anuencia se estableció en julio de 1921 el Partido Comunista Chino (PCC) y, siguiendo las directivas soviéticas, se optó por trabajar y crecer al amparo del Guomindang, al colaborar con los nacionalistas.

Tras la muerte de Sun Yatsen en 1925 -y de Lenin en la Unión Soviética en 1924- la unidad entre el Guomindang y el Partido Comunista Chino terminó. El sucesor de Sun, Chiang Kaishek, consideró a los comunistas como enemigos. En 1927 lanzó una campaña para derrotarlos y persiguió a organizaciones e individuos miembros o afines. Así, se desató la guerra civil. Ambos bandos estaban empecinados en unificar al país y, tras conseguirlo, eliminar al contrincante. Existían, además de estas facciones, caudillos regionales de primer y segundo orden, que eran quienes mantenían el poder local. En la lucha, al inicio, las fuerzas del Guomindang eran superiores a los comunistas, pero la falta de número los favorecía. El peso de mantener un ejército en medio de la inestabilidad económica era un grave problema del Guomindang. Los soldados no estaban disciplinados y prácticamente vivían del botín. Los dirigentes ignoraron esta situación; capital error, porque cerraba el paso de dos recursos vitales para la guerra: la fuerza y decisión humanas y los elementos materiales para ello.

El Partido Comunista, tras una serie de derrotas, logró organizar un cuerpo armado: el Ejército Popular de Liberación (EPL), cuyas directivas eran reclutar a los convencidos -abandonar el sistema de leva obligada- y vivir del terreno (cultivando, cazando, etc.), respetando a las poblaciones. Las tácticas eran distintas y los tiempos para llevarlas a cabo también. Para el Guomindang, el objetivo era una campaña rápida y definitiva, eliminar y en lo posible extirpar a los comunistas; mientras que la estrategia de guerrilla mostró su adecuación tras las derrotas iniciales y se implementó en el EPL. La táctica de prolongar su presencia, aunque sin conservar ciudades, llevó a los comunistas a evaporarse y no presentar batalla campal contra las fuerzas del Guomindang. Era una carrera a destiempo, en la que el lado más fuerte -aparentemente el Guomindang- se debilitaba al no terminar con su oponente, mientras que el PCC con su sola persistencia lograba una victoria moral en sus fuerzas y desacreditaba al contrario.

En una guerra de esta manera, lo peor que le podía pasar a Chiang Kaisek era enfrentarse a un liderazgo unificado y, de cierta forma, radical. El peor escenario se le presentó al Guomindang cuando Mao Zedong, tras la Larga Marcha, consiguió establecerse como el líder del PCC y, por ende, del EPL. 
La utopía y la experiencia de viaje a la República Popular China: el prisma ideológico en Vicente Lombardo Toledano y Pablo Neruda (1949-1951)

LUIS ABRAHAM BARANDICA MARTÍNEZ

Una nueva circunstancia se sumó a la guerra civil que llevaba 10 años, y fue la invasión japonesa al territorio chino. Unos años antes habían tomado la provincia periférica de Manchuria y restablecido una dinastía manchú títere con Puyi, el último emperador chino, como su gobernante. En efecto, la guerra estalló tras el incidente del 7 de julio de 1937 en el puente Marco Polo, y un nuevo frente se abría ante los dos contrincantes. En esta situación se promovió un frente unido contra el invasor. El PCC y el Guomindang hicieron una forzada tregua y establecieron un frente único contra los japoneses, pero cada uno guardaba sus fuerzas.

Durante la guerra, el Guomindang se vio favorecido económica y materialmente por la ayuda norteamericana, a partir de 1941, contra los japoneses. Sin embargo, la corrupción y la parálisis productiva en China bajo Chiang Kaisek diluyó esta ayuda en partículas de riqueza y fortuna personales, comenzando por la misma familia de Chiang. Por otro lado, las fuerzas comunistas mantenían sus posiciones en zonas agrestes y no vitales para los japoneses, pero el frente unido les permitió propagar sus logros y su estructura.

Una vez que los japoneses se rindieron tras los ataques atómicos a Hiroshima y Nagasaki y la entrada en beligerancia de la URSS, en agosto de 1945, la tenue tregua en China estaba por romperse. El último enfrentamiento parecía alinear las fuerzas del Guomindang al apoyo anglo-norteamericano, mientras que el Ejército Popular de Liberación gozó de la inacción de las fuerzas soviéticas y pudo ocupar armas y pertrechos japoneses y una franja territorial en Manchuria.

La versión oficial de los vencedores es que la superioridad moral e ideológica se contrapuso a la corrupción e ineficacia para dar la victoria a los comunistas y la derrota a los nacionalistas. Sin embargo, al inicio de la campaña parecía darse un resultado distinto. La ineptitud de las fuerzas del Guomindang y la falta de modificación en su táctica llevó al desastre, a las líneas de abastecimiento extendidas y a la defección de secciones enteras del ejército.

Tras varias campañas victoriosas, los comunistas tomaron Beijing. Mientras los restos de las fuerzas nacionalistas eran eliminados, el grueso de ellas se refugió en la isla de Taiwán, donde hasta hoy en día se conserva la República de China.

El Partido Comunista Chino y su brazo armado, el Ejército Popular de Liberación (EPL), establecieron la República Popular China con el triunfo militar completo (Chassin, 1965; Clubb, 1972; Evans, 1989; Fairbank; Fairbank y Feuerwerker, 2008; Fitzgerald, 1964; Schurmann y Schell, 1971). La unificación de la nación en un Estado, excepto aquellos que huyeron a la isla de Taiwán, significó un nuevo comienzo tanto estatal como ideológico, ahora bajo la bandera del marxismo-leninismo. Mao Zedong proclamó el 30 de septiembre de 1949: 
Todos tenemos la convicción de que nuestro trabajo quedará inscrito en la historia de la humanidad y demostrará que el pueblo chino, que constituye una cuarta parte del género humano, ya se ha puesto en pie. Los chinos hemos sido siempre una gran nación valiente y laboriosa, y sólo en los tiempos modernos nos hemos quedado atrás. Este atraso se debió exclusivamente a la opresión y explotación del imperialismo extranjero y de los gobiernos reaccionarios del país. (Tsetung, 1977, tomo V, pp. 11-15)

\section{E1 Peregrino político moderno en el bloque comunista: un invitado}

Antes de iniciar el análisis de viajeros latinoamericanos a la República Popular China es preciso anotar un antecedente en la Rusia soviética. Entre los primeros mexicanos de relevancia a los que, aunque no eran militantes, se les permitió viajar a la URSS se hallóAbelardo L. Rodríguez, que para 1936 era expresidente mexicano. En sus memorias apunta:

Cuando estuvimos radicados en Londres, durante poco más de un año contado de 1936 a 1937, se hablaba tanto de Rusia, de sus proezas en el orden materialista, de sus actividades políticas y administrativas, de su nueva constitución, etcétera, que no pude resistir mis deseos de conocer de cerca y verificar personalmente lo que tanto propagaban en el exterior las autoridades soviéticas. Especialmente me interesaba conocer los sistemas que aplicaban en las labores y en el desarrollo de sus granjas colectivas [...]. (Rodríguez, 2003, p. 171)

Logró visitar la URSS junto con Alfonso Verdugo, por medio del embajador soviético Mansky, quien les gestionó los pasaportes. Tras una descripción concluye, desilusionado, aunque cabe mencionar que la autobiografía de Rodríguez fue impresa en 1962: “Allí más que nunca confirmé mi sentir, mi convicción de que nuestra Constitución mexicana, era la más avanzada del mundo, primero por sus postulados y luego porque en México los destinos de la Patria se rigen por ella [...]" (Rodríguez, 2003, p. 202). La vertiente nacionalista mexicana también se hacía presente en la perspectiva hacia el comunismo, pues al fin y al cabo el régimen también era nacido de un proceso revolucionario y también transformaba la sociedad mexicana. Este es un hecho peculiar en el que ambos, el invitado y el anfitrión, comparten el nacionalismo revolucionario, cuyo núcleo es la justicia y las demandas sociales.

Definitivamente las noticias de la URSS en el exterior eran cuidadosamente controladas por el aparato estatal, cuestión que aprenderá el régimen chino. Abundaban la propaganda y las consignas. No obstante, durante buena parte del gobierno de Josef Stalin no se contaba con pruebas de los excesos dentro del sistema. 
La utopía y la experiencia de viaje a la República Popular China: el prisma ideológico en Vicente Lombardo Toledano y Pablo Neruda (1949-1951)

LUIS ABRAHAM BARANDICA MARTÍNEZ

En la organización de la III Internacional Comunista COMINTERN, en 1919, con el papel destacado de Lenin, la perspectiva de una revolución mundial parecía concretarse, y más aún con la implementación de una centralización administrativa de la planificación económica. Así, la racionalización alcanzaba el cénit en las decisiones de la élite. La planificación permitió concentrar el esfuerzo nacional en el proceso industrializador y paliar hasta cierto punto la debacle sistémica de 1928, con el crack de la bolsa. Al mismo tiempo, la organización masiva en sectores y la conformación de organizaciones permitieron la ideologización de las masas en el movimiento comunista internacional. Tal eficiencia planteaba un reto y era el canto de sirena para aquellas regiones en búsqueda de un modelo de desarrollo político, industrial, ideológico. En estas circunstancias, el interés desde América Latina por esta nueva forma estatal era no solo un compromiso moral, también una conveniencia política.

El entorno era la Guerra Fría. En ese escenario, individuos y asociaciones actuaban de forma organizada sin ser parte de aparatos estatales por lo menos nominalmente-, apoyando de forma política, cultural o sindical a uno de los bandos en la disputa. Al mismo tiempo, los regímenes aprovechaban a los sujetos por sus inclinaciones ideológicas o políticas; así, varios artistas - pintores, escritores y poetas- que fundaron o fueron miembros de instituciones, en algunos casos, del mismo Partido Comunista local, eran invitados en comitiva para visitar al país. Por su parte, otras agrupaciones se conformaron con objetivos globales y así actuaban. Fomentaban foros, conferencias, encuentros o festivales de carácter internacional.

En el caso de la República Popular China, como en todo el bloque comunista, esas organizaciones no estaban fuera del cuadro estatal e ideológico permitido, aunque nominalmente podían argüir no filiación. Asimismo, se patrocinaban cumbres o reuniones, a través de invitaciones individuales; se empleaban asuntos "positivos" -aparentemente apolíticos- como la paz, el desarme, el acercamiento cultural o exposiciones museográficas que viajaban de un continente a otro, etcétera.

En este trabajo se analizan dos viajeros: el líder sindical mexicano Vicente Lombardo Toledano, quien estuvo en la República Popular China a escasas semanas de fundarse el régimen revolucionario en 1949, y el escritor y poeta chileno Pablo Neruda, que visitó el nuevo Estado en $1951 .{ }^{17}$ En ambos casos se vislumbra la raigambre utópica, ya que a pesar de la destrucción material, tras la guerra de invasión y la civil, ambos

17 Una versión extensa en Barandica, 2013. 
comparten una emotividad empática con sus anfitriones. La solución o el camino de la misma en relación a los problemas sociales, económicos o políticos de la construcción de una sociedad, no estaba alejado en el tiempo sino solo en el espacio.

Vicente Lombardo nació Teziutlán, Puebla, en 1894. Acerca de su recorrido intelectual, político e institucional existen varias obras (Bolívar, 2005; Millon, 1964; Spenser, 2009; Unzueta, 1966). El motivo por el que fue invitado a la República Popular fue su carácter de líder sindical latinoamericano de una organización mundial: la World Federation of Trade Unions (WFTU), nacida en 1945 -también conocida en español como Federación Sindical Mundial (FSM)-; que por iniciativa de la central sindical de la URSS y de otros países europeos conglomeraba a aquellos que tenían la esperanza de que la colaboración entre comunistas y no comunistas se mantuviera después de la guerra. La plana mayor de la FSM estaba constituida por los líderes sindicales de varios países, para el buró ejecutivo se eligió a Vicente Lombardo Toledano y como tal fue miembro de la Primera Delegación Internacional Sindical que visitó la República Popular China, a escasas semanas de su fundación, por lo que se encontraba entre el entusiasmo por el triunfo y la celebración por la victoria.

Lombardo Toledano escribió un Diario de viaje y dictó al regresar a México un ciclo de tres conferencias en la Universidad Obrera, mismas que fueron publicadas. Todo esto de su directa experiencia en la República Popular China.

Sin duda, sus propios intereses como "marxista" se revelan en sus escritos. Existe la duplicidad en esta forma de análisis, ya que se yuxtaponen el aspecto científico de explicar la realidad a partir de sus categorías y el enfoque político-ideológico que, basándose en la lectura de la circunstancia histórica, se transforma en un programa de acción. En otras palabras, la construcción del progreso hacia la utopía. Esta es la razón de que sus textos se puedan analizar en varios niveles. Por mencionar tres, el primero es como un texto de propaganda, genéticamente consecuencia del solo hecho de la existencia de la República Popular China, es decir, un argumento objetivo per se, el argumento de los hechos, ya que fue la segunda ocasión de una victoria comunista en el mundo. La primera vez fue en Rusia, donde la revolución desembocó en la conformación de la URSS, Estado que, por cierto, Lombardo visitó en 1935. El segundo nivel menos programático corresponde a las pinceladas impresionistas de la experiencia del viaje. Por último, un tercero es dar a conocer los procesos históricos de la Revolución China haciendo eco de la versión oficial, convirtiendo a Lombardo en corifeo ideológico.

Para los marxistas, como Lombardo, el hecho mismo de existir la República Popular China ya era un hecho "científico" de análisis ideológico de la realidad. Era el argumento, no necesitaba defensa, no existía duda, pedía 
La utopía y la experiencia de viaje a la República Popular China: el prisma ideológico en Vicente Lombardo Toledano y Pablo Neruda (1949-1951)

LUIS ABRAHAM BARANDICA MARTÍNEZ

Asia. Amśrica

interpretación. Era el camino revolucionario como un destino inapelable, secuencial e incluso explicable y además deseable. Es la manifestación de la voluntad guiada hacia la utopía.

Salió de México en avión hacia La Habana, Cuba, a fines de octubre de 1949, y de allí a Montreal, Canadá. De Montreal tomó un avión con rumbo a Ámsterdam, Holanda. Luego hacia Praga, y por fin apuntó en su Diario en el "mundo nuevo". Aprovechó su estancia en la capital checa para explicar los cambios que había experimentado el país después de haberse convertido -el año anterior- en democracia popular. Su ortodoxia, desde el punto de vista soviético, está plasmada en la descripción del liderazgo de la URSS, tanto en el nivel ideológico como en las políticas de industrialización y planificación económica que han reconstruido mejor al país. El 29 de octubre asistió al despliegue militar con motivo del día de la Independencia Nacional. El apoyo económico y el patrocinio del Estado soviético fue evidente, ya que aviones rusos llevaron a la Delegación sindical de Praga a Moscú. De Praga a Moscú hicieron escala en Lwow y Kiev. Sobre la URSS bajo el liderazgo de Stalin, Lombardo hizo una digresión militante. Cabe mencionar que hasta ese momento había realizado tres viajes: los anteriores en 1935 y 1946, y en el que se encontraba. Lombardo, sin duda, manifiesta su filiación acrítica con la aseveración de que la Segunda Guerra Mundial probó la eficacia de los Planes de Stalin $[i !]$ y:

Hace tres años vi al pueblo ruso dedicado a curar sus numerosas heridas y a organizar su revancha sobre el tiempo con un nuevo Plan Quinquenal que colocaría al país en posesión de un poderío económico enorme y a su pueblo en condiciones de disfrutar [...] del más alto estándar de vida del mundo [...] En sólo tres años (1949) el pueblo ha cambiado, porque ha vuelto a triunfar, ahora ya no con las armas, sino con el esfuerzo creador y con inflexibilidad en su misión. (Lombardo, 2002, tomo V, vol. 6, p. 153) ${ }^{18}$

En Moscú, la Delegación asistió a los festejos del aniversario de la revolución el 7 de noviembre, luego de “decidir" quedarse, seguramente la visita era obligada, pues el Estado soviético los patrocinaba. Salieron de Moscú al día siguiente, el 8 de noviembre. En China, la primera escala fue en la provincia de Manchuria, en Anantzi, donde fueron movilizados jóvenes escolares para la recepción de la Delegación. Por primera vez, Lombardo Toledano tuvo la oportunidad de interrelacionarse "más directamente", es decir, no en un evento preparado y hasta cierta forma escenográfico, con el "pueblo". Este trato personal se dio en el tren, durante una "tertulia en la sala del carro del jefe de

\footnotetext{
${ }^{18}$ El Diario está en las pp. 135-281, las siguientes citas corresponden a esta edición.
} 
los ferrocarriles de Manchuria”. La siguiente escala fue Harbin y nuevamente aparece el trasfondo de la Revolución de Octubre para entender la Revolución China. La Delegación fue recibida en un evento de propaganda al movilizar a los habitantes para asistir a "un gran mitin", con banda de músicos y un presidium. Una congregación donde se le habló al "pueblo" chino agradeciendo su hospitalidad y mostrándose solidarios en su transformación social. El 14 de noviembre arribaron a Chan Chung, donde tras el evento de rigor continuaron hacia Tei Nim Hai, luego a Te zin; en todos los eventos escucharon la Marcha del Ejército de la Octava Ruta como un fondo musical permanente. En Mukden, nuevamente hubo un mitin con "una enorme muchedumbre" que los recibió. En este lugar se incorporó a la comitiva Liu Ning-yi vicepresidente de la Confederación Pan China del Trabajo, el sindicato chino los invitó a un convite. El 15 de noviembre siguieron su camino y la siguiente escala fue Tanshan, donde se organizó otro mitin. Continuaron hacia Tientsin donde fueron recibidos en una "fiesta llena de movimiento y entusiasmo". Los obreros vestían todos de azul y usaban gorras con una pequeña visera.

En Beijing la recepción de la Delegación fue encabezada por la plana mayor de la República Popular China: 刘少奇 Liu Shao-chi, presidente honorario de la Federación Pan China del Trabajo y vicepresidente de la República; Chen Yun, presidente y Li Lisan vicepresidente de la misma Federación; Li Kehnung viceministro de Relaciones Exteriores, en nombre del mismo 周 恩 来 Zhou Enlai; Nieh Jung Chen, alcalde de Beijing; Tsai Chang, presidente de la Federación Pan China de Mujeres Democráticas; Feng Wenpui y Chian Nan-hsiang, secretario y vicepresidente del Comité Central de la Liga Democrática de la Juventud y otras personalidades representativas del nuevo régimen. El tema en común en la cena fue el discurso antiimperialista por el orador de la noche Liu Shao chi. En Beijing se le asignó a Lombardo Toledano (2002) una guía-secretaria llamada Li Li-chiun "una simpática joven [...] nacida en Manila, en donde aprendió un inglés perfecto y cuyos padres han vuelto a la patria". Al día siguiente, el 16 de noviembre de 1949, a poco más de cuarenta días de la proclamación de la República, se instalaron los trabajos de la Conferencia Sindical de los Países de Asia y Australasia en uno de los palacios de la ciudad imperial. En el banquete de bienvenida también presidió Zhou Enlai a quien Lombardo describe como: "[...] un hombre joven, vigoroso, de estatura mediana, de cejas pobladas y nariz recta. Viste de azul oscuro. De su saco, abotonado hasta el cuello, sólo se destaca el broche de la pluma fuente que guarda en una de las bolsas". Mientras que de Chu Teh afirma: "[...] es un hombre de edad madura, con las primeras arrugas en el rostro. Sencillo hasta la humildad. Usa anteojos para leer". Así describe al procurador Shen Chun-ju: "[...] es un viejo de pequeña estatura, de rostro inteligente, cabeza rapada y barba blanca y negra terminada en punta". 
La utopía y la experiencia de viaje a la República Popular China: el prisma ideológico en Vicente Lombardo Toledano y Pablo Neruda (1949-1951)

LUIS ABRAHAM BARANDICA MARTÍNEZ

En Beijing, la Federación Pan China del Trabajo organizó un mitin para saludar a la Delegación -con evidente patrocinio estatal-, así los sectores movilizados montaron una escenografía, un espectáculo de masas. A continuación, la comitiva inició una serie de visitas guiadas que la llevaron desde los museos al mercado, a la comuna, a una muestra de danza y a una visita a la sociedad de artistas. Esto viene enmarcado en el concepto de Nueva Cultura, que era un aspecto de la renovación profunda de la sociedad (Tse-tung, 1976, tomo II, pp. 353-400). Entre lo que le llama la atención a Toledano fue la movilización y organización de los sectores juveniles. La Delegación visitó el Palacio de Verano el 30 de noviembre y todo estaba listo, entonces, para la clausura el 1 de diciembre. El broche de oro de la visita fue un evento doble, primero asistieron a la proyección de un documental acerca de la gran ofensiva del Ejército Popular de Liberación con lo que mostraban a los líderes sindicales internacionales el poder y organización que dieron el triunfo al régimen recién establecido. Segundo, una conferencia de 刘少奇 Liu Shaoqi sobre "los grandes problemas de los países asiáticos y de las perspectivas de la lucha de sus pueblos por la independencia nacional". Ya concluida y clausurada la Conferencia sindical, los visitantes salieron el 4 de diciembre en tren hacia la Unión Soviética, a donde llegaron el 11 de diciembre. Estaban en Moscú el 14 de diciembre. Diez días de viaje en tren desde Beijing. El clima de invierno imposibilitó el regreso aéreo. Continuó Lombardo hasta Praga en tren y tras 15 días desde que salió de la capital china había arribado nuevamente a la capital checoslovaca. En Praga tomó un avión hacia Ámsterdam. Cruzó el Atlántico y llegó del largo viaje tras las escalas en Montreal y La Habana a la Ciudad de México el 20 de diciembre de 1949.

En México se organizaron tres conferencias en la Universidad Obrera de México, institución que fundó el mismo Vicente Lombardo en la Ciudad de México en 1936. El conjunto de las tres exposiciones forma una visión sistematizada de la revolución que dio origen al establecimiento de la República Popular China; en gran parte se hace eco de la versión oficial de los sucesos, después de todo una revolución triunfante tiene varios motivos para argumentar -entre ellos el simple hecho de existir- su correcta interpretación de las circunstancias históricas y de la actividad acertada que desarrollaron hasta la victoria. Estas conferencias fueron pronunciadas los días 15, 16 y 17 de febrero de 1950. "Origen, desarrollo y programa de la Revolución China", el 15; "Estrategia y táctica de la Revolución China", el 16 y "La Dictadura Popular y las perspectivas de la República Popular China", el 17 de febrero de 1950. Su objetivo era dar a conocer al "pueblo" de México las primicias de un nuevo régimen. En el Diario como en las conferencias Lombardo señalaba la energía renovada de las fuerzas chinas, encabezadas por un líder firme y cuya meta es la construcción de la utopía con el carácter ideológico del comunismo. Así era testigo del esfuerzo de gestación de un "nuevo mundo". 
Ricardo Eliécer Neftalí Reyes Basoalto nació en Chile en 1904. Ingresó al Liceo varonil de Temuco, donde cursó sus estudios hasta 1920. El mismo año comenzó su contribución en la revista literaria Selva Austral y adoptó su pseudónimo Pablo Neruda. En 1923 publicó Crepusculario y al año siguiente su famoso Veinte poemas de amory una canción desesperada. Posteriormente aparecieron tres breves libros publicados en 1926: El habitante y su esperanza, Anillos (en colaboración con Tomás Lago) y Tentativa del hombre infinito.

En 1927 comenzó su larga carrera diplomática con el cargo de Cónsul en Rangún, Birmania (hoy Yangoon, Myanmar). Luego pasó a Colombo (Sri Lanka), después Singapur y en 1930 se trasladó a Batavia (hoy Djakarta) en la isla de Java. En 1931 volvió a Chile, pasó a Argentina y hacia 1934 logró el cargo de Cónsul chileno en Barcelona. Durante la Guerra Civil española apoyó a los republicanos y escribió España en el Corazón (1937). Más tarde, en París fue gestor del proyecto Winnipeg, barco que llevaría a cerca de 2000 inmigrantes españoles desde Francia hasta Chile. Poco tiempo después fue asignado como Cónsul General en México, donde reescribe su Canto General de Chile transformándolo en un poema del continente y publicado en México en 1950 como Canto General. A finales de abril de 1949 reapareció en la sesión de clausura del Primer Congreso del Movimiento Mundial de Partidarios de la Paz en París y fue nombrado miembro del Consejo Mundial de la Paz. En el II Congreso del Movimiento Mundial de Partidarios de la Paz, en Varsovia, Polonia en noviembre de 1950, recibió junto con Pablo Picasso, Paul Robeson y otros, el Premio Internacional de la Paz, que en el caso de Neruda fue por su poema "Que despierte el leñador". Ese mismo año, 1950, se dio a conocer en Moscú la creación del Comité Internacional del Jurado del Premio Stalin por la Consolidación de la Paz entre los pueblos. Entre los miembros estaba el poeta. Después de una estancia de vuelta en París, en marzo de 1951 se encontraba en Moscú y asistió a la fiesta del Primero de Mayo, luego fue a Praga y se instaló. En este momento dependía delestipendio de los comunistas y ellos controlaban su agenda. Neruda era un corifeo del mundo socialista, sus invectivas iban en contra del "mundo libre".

En esta circunstancia fue elegido como delegado al Congreso Mundial de la Paz en China. Viajó en tren, cumpliendo su deseo de conocer Siberia, aunque fuese por la ventana de un vagón. El 14 de septiembre llegó a Irkutsk, donde transbordó del tren a un avión. El 18 de septiembre, día de la independencia de Chile, en una ceremonia en Beijing se entregó el Premio Stalin, de cuyo jurado Neruda era miembro, a Song Qinglin, viuda de Sun Yatsen. En esta ocasión Neruda leyó su poema "Esta medalla", que se publicaría más tarde en su obra Las uvas y el viento.

Recuerda en sus memorias las sonrisas de los chinos y las clasifica en auténticas y en nerviosas. "El pueblo chino es uno de los más sonrientes del 
La utopía y la experiencia de viaje a la República Popular China: el prisma ideológico en Vicente Lombardo Toledano y Pablo Neruda (1949-1951)

LUIS ABRAHAM BARANDICA MARTÍNEZ

Asia Amśrica
Lstins

mundo", pero: "hay dos clases de sonrisas chinas: hay una natural que ilumina los otros colores de trigo. Es la de los campesinos y el vasto pueblo. La otra es una sonrisa de quite y pone, postiza... es la sonrisa de los funcionarios" (Neruda, 1981, pp. 285-293).

A razón de su visita escribe "Saludo a China", que, con modificaciones, sería la base de los poemas, también publicados en Las uvas y el viento: "China", "La gran marcha" y "El gigante".

En general, Neruda recuerda en su primera visita que los chinos vestían de azul, igual hombres y mujeres, no había personas en harapos -aunque tampoco automóviles-; había escasez y dificultades. Aquí analizamos al detalle dos experiencias; son las que vienen a su mente con nitidez. Años después las refirió:

\section{V.1 Los calcetines}

Lo que nos preocupaba especialmente a Ehrenburg ${ }^{19}$ y a mí, eran pequeños detalles, pequeños tics del sistema. Cuando quisimos comprar un par de calcetines, un pañuelo, aquello se convirtió en un problema de estado. Los compañeros chinos discutieron entre sí. Luego de nerviosas deliberaciones partimos del hotel en caravana. A la cabeza iba nuestro coche, luego el de los guardias, el de los policías, el de los intérpretes. La manada de coches arrancó velozmente y se abrió camino por entre la siempre apiñada multitud... llegados al almacén, bajaron deprisa los amigos chinos, expulsaron con rapidez a toda la clientela de la tienda, detuvieron el tráfico, formaron una barrera con sus cuerpos, un pasadizo humano que atravesamos cabizbajos Ehrenburg y yo, para salir luego igualmente cabizbajos quince minutos después, con un paquetito en la mano y la más ferviente resolución de no comprar nunca más un par de calcetines [...]. (Neruda, 1981, pp. 285-293)

Es de señalar que esos pequeños tics se refieren a la inequidad y al trato diferenciado, al mismo tiempo de mostrar que los invitados solo son testigos de una escenografía. Aunque el hecho de minimizarlos también realza la capacidad del régimen, ya que en plena construcción se debe ser consciente de aquellas pequeñas señales para modificarlas. En otras palabras, son resquicios donde la reconstrucción y la utopía en la realidad no habían llegado. Evidentemente implicaría que en lo demás sí se encuentran en una sociedad más justa e igualitaria.

\section{2 E1 restaurante}

${ }^{19}$ Su compañero de viaje era Iliá Ehrenburg (1891-1967), fue un escritor soviético.

Asial AméricaLatina, vol. 5, no 9, (2020), pp. 11-40. DOI: 10.33177/9.2 
La utopia y la experiencia de viaje a la República Popular China: el prisma ideológico en Vicente Lombardo Toledano y Pablo Neruda (1949-1951)

LUIS ABRAHAM BARANDICA MARTÍNEZ

[...] dígame en el caso del restaurante voy a contar. En el hotel nos servían la pésima comida inglesa que dejaron como herencia en China los sistemas coloniales. Yo, que soy un gran admirador de la cocina china, le dije a mi joven intérprete que ardía en deseos de disfrutar del afamado arte culinario pekínes. Me respondió que lo consultaría. Ignoro si realmente lo consultó, pero lo cierto es que seguimos mascando el desabrido rosbif del hotel. Le volví a hablar del asunto. Se quedó pensativo y me dijo: los compañeros se han reunido varias veces para examinar la situación. El problema está a punto de resolverse. Al día siguiente se nos acercó un miembro prominente del comité de acogida... [le preguntó si querían comer comida china a lo que contestó que si] el asunto difícil - dijo el chino- casi imposible. Ehrenburg sonrió como un escéptico. Yo me enfurecí -compañero- le dije hágame el favor de arreglarme mis papeles de regreso a París. Si no puedo comer comida china en China, la comeré en el barrio latino, donde no es ningún problema. Mi violento alegato tuvo éxito. Cuatro horas más tarde, precedidos por nuestra profusa comitiva, llegamos a un famoso restaurante donde desde hace 500 años se prepara el pato a la leca. El restaurante abierto día y noche, distaba apenas 300 metros de nuestro hotel. (Neruda, 1981, pp. 285-293)

Nuevamente, esos tics del sistema muestran la tarea titánica y, al mismo tiempo, la medida humana de la transformación de la sociedad. El progreso material y la abundancia parecía dispuesta, solo que existía un estricto protocolo y aquello significaba que no había libertad de movimiento para los invitados, eran cautivos en lo que se quería que se viese. Es decir, en cierta manera era evidente la manipulación; pero ni Lombardo ni Neruda se extienden sobre ello.

El 12 de octubre Neruda regresó a Moscú. Siguió hacia Viena y en diciembre de 1951 se encontraba nuevamente en la capital soviética en su función de miembro del Jurado del Premio Stalin.

En suma, a pesar de que Neruda era un artista patrocinado, años después apunta ciertas impresiones desfavorables del sistema. Una vivencia que hasta cierto punto señala lo difícil que es emparejar la utopía a la vida cotidiana.

\section{Conclusión. Técnicas de hospitalidad, la interpretación de Hollander y la utopía.}

A manera de conclusión se rescata el análisis de Paul Hollander, quien señala que la premisa de un invitado de los regímenes políticos no es que se le mienta y engañe, sino que en sus palabras reciba un tratamiento como posible 
La utopía y la experiencia de viaje a la República Popular China: el prisma ideológico en Vicente Lombardo Toledano y Pablo Neruda (1949-1951)

LUIS ABRAHAM BARANDICA MARTÍNEZ

Asia Amb́rice

VIPP (Very Important Potential Propagandist, Muy Importante Propagandista Potencial). Es decir que no se ocultaban ominosamente los problemas, pero se les contrastaba con la promesa que se estaba cumpliendo ante sus ojos: la de construir una sociedad igualitaria, equitativa y justa. Así, lo que se busca no es el engaño burdo sino el compromiso de los invitados con el objetivo ideológico y, sobre todo, con la promesa utópica.

Aquí cabría apuntar que, en todo caso, para el que analiza los procesos con la perspectiva del tiempo, no es malo ser engañado, es más complejo querer serlo. Y esas motivaciones son las que enmarcan la carga ideológica al ver la realidad. En este sentido, los relatos de los viajeros latinoamericanos a la China comunista retratan no una panacea, pero sí la promesa de un proyecto utópico. La realidad vista es interpretada y se transforma, cobra otro cariz y permite plasmar las dificultades y obstáculos materiales, a los que se confrontan elementos como convencimiento, unidad, voluntad. En las noticias de viajeros son palpables las dificultades, al igual que la confianza en la posibilidad de un futuro utópico.

Por otra parte, existen varias formas de hacer sentir al invitado, de hacerle experimentar y de convencerle de forma suave (Hollander, 1998). Entre las más representativas del régimen soviético, y que el Estado comunista chino imitó, no por falta de imaginación sino porque ya existía el modelo, es la invitación en comitiva; esto permitía implementar un eficiente y barato transporte controlado, guía amigable y la libertad medida de movimientos (es decir, el itinerario conocido de antemano), garantizando las visitas y el contacto mediado, vigilado, tanto a los pueblos como a las fábricas, hospitales, presas, escuelas, cárceles y demás infraestructura modelo. En los recorridos se explicaba que de esa forma serían -nuevamente en un futuro-todas las que se realizarían en adelante. En suma, la construcción del nuevo mundo, como le llamaba Lombardo, iría por la senda del progreso constante, de una manera inmediata.

La distancia de la lengua hizo posible el control de noticias, y la única vía sería la relación "personal" en los banquetes, cenas o entrevistas con la élite gobernante; de esta forma, la ligazón personal se convertía en solidaridad. La crítica controlada de los retos del Estado, que garantizaba la premisa del proceso de construcción, de transformación de la sociedad, etcétera. En conclusión, el trato preferencial y cercano del régimen con sus invitados los convertía ya sea en camaradas o en testigos empáticos. De igual forma que Raphael Hytholday, constatan las circunstancias de sociedad distante en el espacio, pero simultánea, aunque Lombardo y Neruda no son simples visitantes, son comprometidos correligionarios. Las promesas, la reconstrucción y el ánimo de triunfo son patentes, al igual que la confianza en superar los obstáculos. En las fechas en que escribieron aún no se confrontaba la realidad denunciada en el XX Congreso del PCUS, las purgas y los enormes 
sacrificios en vidas humanas de la transformación revolucionaria y el régimen férreo estalinista.

En el caso de la República Popular China, una nueva oportunidad para el proyecto utópico comunista significaba que, si en la URSS hubo errores corregibles en el proceso, en China era posible hacerlo sin tantos traspiés, aprovechando la experiencia ajena. En sus inicios, el régimen, simplemente al poner orden en un caos de lucha civil, representaba una promesa cumplida. Un hecho que daría cimiento a un orden futuro más justo. A diferencia de la senda soviética, China emergía como una promesa de construir una sociedad mejor sin los excesos y desastres de la Unión Soviética. Además de no enfrentar aislada la intervención extranjera, la marginación internacional y sin contar con aliados. Cabe mencionar que el núcleo discursivo de un futuro promisorio y de sacrificarse por ello, no fue ni es exclusivo de la ideología comunista, también lo es de otras construcciones discursivas. En el caso de Latinoamérica, un ejemplo de un cuerpo de ideas que también ocasionó lo contrario de lo que prometía, encauzando esfuerzos utópicos en la construcción distópica, fue la aplicación de la idea del desarrollo (Escobar, 2012).En conclusión, los relatos de viajeros, ya sean ficticios como el que escribió Moro, o reales, como los aquí analizados, ofrecen un material propicio para el análisis a varios niveles $\mathrm{y}$, en este caso, con una pesquisa que ligó diferentes explicaciones en el hilo conductor de las ideas y de su aplicación en la realidad.

\section{VII.Referencias bibliográficas}

AnÓNIMO. (2012). El obelisco revolucionario del jardín de Alejandro. Moscú de la Revolución. Un Paseo por el Moscú Soviético. Recuperado en: https://moscudelarevolucion.blogspot.mx.

ANÓNimo. (2014). Un año después de la desaparición del obelisco revolucionario del jardín de Alejandro. Moscú de la Revolución. Un Paseo por el Moscú Soviético. Recuperado en: https://moscudelarevolucion.blogspot.mx

Ackyrod, P. (2003). Tomas Moro. Barcelona, España: Edhasa.

Aramayo, R. R. (2001). Kant y la Ilustración. Isegoría, Revista de Filosofía moral y política, (25), pp. 293-309.

Barandica Martinez, L.A. (2013). De viajeros, ideas y propaganda. Latinoamérica y la China Popular. Primeras impresiones de militantes, periodistas y políticos (19491972). México: Palabra de Clío.

Bianco, L. (1970). Los orígenes de la revolución cbina 1915-1949. Caracas, Venezuela: Editorial Tiempo Nuevo.

Bolívar Meza, R. (2005). Vicente Lombardo Toledano: vida pensamiento y obra, México, Instituto Politécnico Nacional. 
La utopía y la experiencia de viaje a la República Popular China: el prisma ideológico en Vicente Lombardo Toledano y Pablo Neruda (1949-1951)

LUIS ABRAHAM BARANDICA MARTÍNEZ

Breve historla moderna de ChinA. (1980). Beijing, China: Ediciones en

Lenguas Extranjeras.

Bury, J. B. (1971). La idea del progreso. Madrid: Alianza Editorial.

Bury, J. B. (1920). The Idea of Progress. An Inquiry into its origin and growth.

Londres: McMillan. CARR, E.H. (1966). The Bolshevike Revolution $1917-$

1923. Londres: Penguin Books, 3 vols.

Chassin, L.M. (1965). The Communist Conquest of China: A History of the Civil War, 1945-1949, Cambridge, Mass.:Harvard University Press.

Chesneaux, J. (editor) (1972). Popular Movements and Secret Societies in China, 1840-1950, Stanford, California: Stanford University Press.

Clubb, O.E. (1972). 20th Century China, 2 ed. New York: Columbia University.

CONDORCET, M.J. (1822). Esquisse d'un tableau historique des progrès de l'esprit bumain. París:Masson et fils.

Cosser, L.A. (1980). Hombres de ideas. El punto de vista de un sociólogo. México: Fondo de Cultura Económica.

Davis, J.C. (1985). Utopia y la sociedad ideal. Estudio de la literatura utópica inglesa 1516-1700.

México: Fondo de Cultura Económica.

Durkheim, E. (1987). El Socialismo. Madrid: Ediciones Akal.

Escobar, A. (2012). La invención del desarrollo. Bogotá, Colombia: Universidad del Cauca. Evans, H. (1989). Historia de China desde 1800. México: El Colegio de México, Centro de Estudios de Asia y África.

FAIrbank, J.K. (1942). Tributary Trade and China's Relations with the West, The Far Eastern Quarterly, vol. 1, (2), pp. 129-149.

Fairbank, J.K. (1995). The creation of the treaty system. En J.K. Fairbank (editor), The Cambridge History of China, vol. 10, Late Ch'ing, 1800-1911, part I (pp.213-265). New York: Cambridge University Press.

Fairbank, J.K. (editor) (2008). The Cambridge History of China, vol. XII Republican China 1912-1949, part 1, New York: Cambridge University Press.

FAirbank, J.K. y Feuerwerker, A. (EDs.). (2008). The Cambridge History of China, vol. XIII Republican China 1912-1949, part 2. New York: Cambridge University Press.

Fitzgerald, C.P. (1964). The Birth of Communist China, Harmondsworth: Penguin Book. Furey, C.M. (2006). Erasmus, Contarini, and the Religious Republic of Letters. Cambridge y New York: Cambridge University Press.

Herrera, F. DE (2001). Tomas Moro. Sevilla, España: Secretariado de publicaciones de la Universidad de Sevilla.

Hollander, P. (1998). Political pilgrims: Western Intellectuals in search of the Good Society, 4 ed., New Brunswick, N.J.

Hollander, P. (2016). From Benito Mussolini to Hugo Chavez Intellectuals and a Century of Political Hero Worship, Cambridge University Press.

Jaeger, W. (2002). Paideia. Los ideales de la cultura griega. México: Fondo de 
La utopia y la experiencia de viaje a la República Popular China: el prisma ideológico en Vicente Lombardo Toledano y Pablo Neruda (1949-1951)

LUIS ABRAHAM BARANDICA MARTÍNEZ

Cultura Económica.

Jones, S.M. Y Khun P.A. (1995). Dynastic decline and the roots of rebellion.

En J.K. Fairbank (editor), The Cambridge History of China, vol. 10, Late

Ch’ing, 1800-1911, part I (pp. 107-162). New York: Cambridge

University Press.

KANT, I. (1994). Ideas para una historia universal en clave cosmopolita y otros escritos sobre

Filosofía de la Historia, 2 ed. Madrid: Tecnos.

Kautsky, K. (1888). Thomas More und seine Utopie, mit einer historische Einleitung.

Stuttgart: Verlag von J.G.W. Dieh.

Kristeller, P.O. (1982). El pensamiento renacentista y sus fuentes. México: Fondo de Cultura Económica.

Lombardo Toledano, V. (2002). Diario de un viaje a la China Nueva. En V.

Lombardo Toledano, Obra Histórico-Cronológica, Tomo V, Vol. 6(pp.

135-281). México: Centro de Estudios Filosóficos, Políticos y Sociales

"Vicente Lombardo Toledano".

Mannheim, K. (2004). Ideología y utopia, Introducción a la sociología del conocimiento, 2 da edición.

México: Fondo de Cultura Económica.

Makito, S. (2011). The Sino-japanese $W$ ar and the Birth of Japanese Nationalism.

Tokyo, Japón: International House of Japan.

Malena, J.E. (2012). El concepto chino de Justicia: sus definiciones etimológica y filosófica, y su administración (mediante dos estudios de caso) en la

República Popular. Instituto Superior de Estudios Religiosos -ISER, (3).

Recuperado en:

https://iser1968.files.wordpress.com/2012/12/malenacmp.pdf

Marius, R. (1999). Thomas More: A Biography. 2 ed. Cambridge y Londres: Harvard University Press.

Millon, R.P. (1964). Lombardo: biografía intelectual de un marxista mexicano. México: Universidad Obrera.

Moro, T. (2011). Utopía. Madrid: Círculo de Bellas Artes.

Morodo Leoncio, R. (2016). El laberinto utópico de Tomas Moro. Discurso en la Real Academia de Ciencias Morales y Políticas, Anales de la Real Academia de Ciencias Morales y Políticas (España), (93), pp. 65-84.

Morvs, T. (1895). Vtopia. Berlín: Weidmannsche Buchhandlung.

Neruda, P. (1981). Confieso que he vivido (Memorias), 6ª ed. Barcelona, España: Editorial Seix Barral.

Neumeister, S. (2010). La utopía moral de un héroe político-cristiano: El Tomás Moro de Fernando de Herrera. En E. Fosalba Vela y C. Vaillo (Coords.), Literatura, sociedad y politica en el Siglo de Oro (pp.147-158). Barcelona, España: Universitat Autònoma de Barcelona.

Nisbet, R. (1986). La idea de progreso, Revista Libertas, (5), 30 pp.

NorTh, R.C. (1965). El comunismo chino. Madrid: Ediciones Guadarrama 
La utopía y la experiencia de viaje a la República Popular China: el prisma ideológico en Vicente Lombardo Toledano y Pablo Neruda (1949-1951)

LUIS ABRAHAM BARANDICA MARTÍNEZ

(Biblioteca para el Hombre Actual, 4).

Priestland, D. (2010). Bandera Roja. Historia politica y cultural del comunismo.

Barcelona, España: Crítica.

Ricoeur, P. (2008). Ideología y utopía. Barcelona, España: Gedisa.

Rodríguez, A.L. (2003). Autobiografía, 2da edición. México: Senado de la República.

Schurmann, F. y Scheld, O. (1971). China Republicana. El nacionalismo, la guerra y el advenimiento del comunismo, 1911-1949. México: FCE.

SiLVA, A. DE (COMP.). (1998). Un hombre para todas las horas: la correspondencia de Tomás Moro (1499-1534). Madrid: Ediciones Rialp.

Spenser, D. (2009). Vicente Lombardo Toledano envuelto en antagonismos internacionales, Revista Izquierdas, año 3, (4), pp.

Tsetung, M. (1976). Sobre la Nueva Democracia (Enero, 1939). En Tsetung, M., Obras Escogidas de Mao Tsetung (tomo II, pp. 353-400). Pekín, China: Ediciones en Lenguas Extranjeras.

Tsetung, M. (1977). El pueblo chino se ha puesto en pie. En Tsetung, M., Obras Escogidas de Mao Tsetung (tomo V, pp. 11-15). Pekín, China: Ediciones en Lenguas Extranjeras.

Turgot, A.R.J. (1991). Discursos sobre el progreso humano. Madrid: Tecnos.

Unzueta, G. (1966). Lombardo Toledano y el marxismo-leninismo. México: Fondo de Cultura Popular.

Wells, A. (2001). The Political Thought of Sun Yat-sen Development and Impact. New York: Palgrave.

Wilson, E. (1972). Hacia la estación Finlandia. Ensayo sobre la forma de escribiry hacer historia. Madrid: Alianza editorial.

Yoran, H. (2010). Between Utopia and Dystopia. Erasmus, Thomas More, and the Humanist Republic of Letters. Playmouth, Reino Unido: Lexington Books.

Zeitlin, I.M. (2001). Ideología y teoría sociológica, 2 ed. Buenos Aires: Amorrortu.

Zeituin, I.M. (1968). Ideology and development of the sociological theory, New Jersey: Prentice-Hall. 

